\title{
A STUDY ON THE CUTANEOUS MANIFESTATIONS OF DIABETES MELLITUS
}

\author{
by Neerja Puri
}

comment:

Dr. Al-Mashaleh Manal Sulaiman

Our Dermatol Online. 2012; 3(2): 87

Date of submission: 02.02.2012 / acceptance: 05.02.2012

Conflicts of interest: None

Nearly one-third of diabetic patients have some type of dermatologic manifestation [1]. With time, the skin of all diabetic patients is affected in some form or another. Dermatologic manifestations of the disease can range from the more benign granuloma annulare to the more sinister diabetic ulcer [2]. Cutaneous signs of DM are extremely valuable to the clinician. For example, diabetic bullae, diabetic dermopathy, necrobiosis lipoidica diabeticorum, and the scleroderma-like syndrome of waxy skin with limited joint mobility can alert the physician to the diagnosis of diabetes. Eruptive xanthomas reflect the status of glucose and lipid metabolism. Cutaneous signs appear to be closely linked to increased glycosylated haemoglobin, an indicator of poor control of blood glucose levels [3]. The importance of cutaneous manifestations in diabetic patients is highlighted by Puri in an elegant study published in our journal. The author had looked thoroughly into the prevalence and pattern of cutaneous manifestations in diabetic patients and its correlation to disease duration and status, the author also mentioned other rare cutaneous diseases and its relation to diabetes mellitus. As emphasized in the article recognition of these findings is a key for treatment and prevention. This article will add more awareness and benefits to the physician and patient toward better health and clinical outcome.

\section{REFERENCES}

1. Perez MI, Kohn SR: Cutaneous manifestations of diabetes mellitus. J Am Acad Dermatol. 1994; 30: 519-531; quiz 532-534.

2. Meurer M, Stumvoll M, Szeimies RM: [Skin changes in diabetes mellitus]. Hautarzt. 2004; 55: 428-435.

3. Shahzad M, Al Robaee A, Al Shobaili HA, Alzolibani AA, Al Marshood AA, Al Moteri B: Skin manifestations in diabetic patients attending a diabetic clinic in the Qassim region, Saudi Arabia. Med Princ Pract. 2011; 20: 137-141.

\section{Correspondence:}

Dr. Al-Mashaleh Manal Sulaiman

King Hussein Medical Center, Royal Medical Services, Amman, Jordan

E-mai: manal mashaleh@yahoo.com 